\title{
-Erratum for the paper "Kalogeraki A, Tamiolakis D, Mavrigiannaki P, Karvelaskalogerakis M, Datseri G, Agelaki S, Papadopoulos S. Recurrent Cerebellar Desmoplastic/Nodular Medulloblastoma in Cerebrospinal Fluid (CSF) in the Elderly. A Cytologic Diagnosis. Rom J Intern Med. 2016; 54(2):137-9"
}

\author{
ALEXANDRA KALOGERAKI \\ ${ }^{1}$ University of Crete, Medical Faculty, Greece
}

\section{Dear Editor,}

Please note that:

1. Authors listed are as follows: Alexandra Kalogeraki, Dimitrios Tamiolakis Panagiota Mavrigiannaki, Michael Karvelas-Kalogerakis, Sophia Agelaki, Savvas Papadopoulos. Doctor Galateia Datseri who is not included any more was not involved in the design and the performance of the study, was unaware of been listed among authors, so she wishes her name to be removed.

\section{INTRODUCTION page 137}

We change the last two sentences as follows:

Desmoplastic MB exhibits distinctive cytopathologic features in intraoperative smears. The occurrence in adults and the presence of astroglial elements in imprint smears may result to erroneous diagnosis as gliomas [10].

\section{CASE REPORT page 138}

We correct the last three sentences (histopathological findings, treatment and follow-up) as follows:

Histopathological examination of the tumor mass biopsy specimen revealed areas of poor cellularity surrounded by densely packed hyperchromatic cells which reacted positively with neuron specific enolase (NSE). Low dose radiation and chemotherapy consisting of lomustine, cisplatin, hydroxyurea, and vincristine were administered.

The patient is disease free, by MRI, three months after recurrence.

\section{DISCUSSION page 138-139}

We correct the last two paragraphs as follows:

The recurrence rate for medulloblastomas in adults ranges from $50 \%$ to $60 \%$. The most common site of recurrence is the posterior fossa, followed by the spine, CSF, supratentorial cerebrum, bone, and other extraneural sites $[14,15]$.

CSF cytology sensitivity in detecting neoplastic involvement from medulloblastoma ranges from $43 \%$ to $62 \%$. The percentages of positive CSF cytologic results for medulloblastoma are higher than for other CNS tumors and this may be caused from various reasons [16].

Fouladi et al. reported that: "with the use of either CSF cytology or spinal MRI alone, leptomeningeal involvement would be missed in up to $14 \%$ to $18 \%$ of patients with medulloblastoma and thus, both CSF cytology and spinal MRI should routinely be used" [17].

We apologize for the inconvenience. 
Correspondence to: Alexandra Kalogeraki, MD, $\mathrm{PhD}$. University of Crete,

Medical Faculty, PO Box 1393, Heraklion 71110, Crete, Greece

Tel: + 302810394692 , Fax: +30 2810394694 ,

E-mail: kalogerakimed@yahoo.gr

\section{REFERENCES}

KALOGERAKI A, TAMIOLAKIS D, MAVRIGIANNAKI P, KARVELASKALOGERAKIS M, DATSERI G, AGELAKI S, PAPADOPOULOS S. Recurrent Cerebellar Desmoplastic/Nodular Medulloblastoma in Cerebrospinal Fluid (CSF) in the Elderly. A Cytologic Diagnosis. Rom J Intern Med. 2016; 54(2):137-9.

Received December 15, 2016 